\title{
THE EFFECTIVNESS OF USING MOBILE TECHNOLOGY IN IMPROVING STUDENTS' VOCABULARY
}

\author{
Aigerim Dzhamperova ${ }^{1}$, Zhanar Eskazinova² \\ ${ }^{1}$ E.A. Buketov Karaganda University, Karaganda, Kazakhstan \\ ${ }^{2}$ E.A. Buketov Karaganda University, Karaganda, Kazakhstan \\ ORCID ID D : 0000-0001-8307-9014
}

\begin{abstract}
The article introduces the study of the application of mobile technology in order to improve students' vocabulary. Smartphones have become a part of our life with their applications used extremely varied. In language learning, the use of these applications has opened up new possibilities, innovatively shaping the teaching and learning methods of students. One of these methods is mobile technologies, which can improve students' vocabulary, speaking in learning English language. Some of the main advantages of using mobile technologies are intuitive navigation on the Internet resource, ease and clear presentation and assimilation of information, quick access to necessary materials.
\end{abstract}

\section{INTRODUCTION}

The word is the main meaningful unit of the language. Words denote specific objects and abstract concepts, express feelings and intentions. Words are also a communication tool.

Vocabulary is the basis for developing skills and achieving competence in learning a foreign language. Also, vocabulary is a core of foreign language learning, idiomatic expressions are the most frequently used non-literal expressions, and building blocks of daily conversations in a language, so lack of ability to use them competently can cause communication problems for the language learner such as sounding unnatural and inauthentic. [Cooper, 1998]. The richness of the vocabulary is a sign of the high development of both society as a whole and each individual person. Therefore, the school attaches great importance to the work on the vocabulary of students. The peculiarity of vocabulary work at school is that it is carried out in the process of all the teaching and educational activities of the teacher. What does vocabulary work at school consist of? Four directions merge in it:

First, the enrichment of the vocabulary, the assimilation of those new words that schoolchildren did not previously know at all, new meanings of words;

Second, the clarification of the vocabulary, the deepening of understanding of already known words, the clarification of their shades, the differences between synonyms, the selection antonyms, analysis of polysemy.

Thirdly, the activation of the vocabulary, the inclusion of the widest possible range in the speech of each student, the introduction of words into sentences, the assimilation of the compatibility of words with other words, the appropriateness of their use in a particular text;

Fourthly, the elimination of non-literary words sometimes used by younger students, the correction of erroneous pronunciations. It's expected that all four areas of work are closely related.

Also, vocabulary work is planned so that no more than 3-5 new words are entered into the vocabulary of students in one lesson, and with a few more words, work would be carried out to clarify the meanings, clarify their meanings.[Hayati, Jalilifar \& Mashhadi, 2013]

In practice, a variety of techniques are used to work on the meaning of a new word. This ensures students' interest in vocabulary activity, allows them to enter a new word in the most rational way for each case.

Today there are many ways to show new words and learn them further. Along with new technologies, we are exploring all the ways to apply them in the educational process.

The past decade has seen the rapid development in using smartphones in vocabulary teaching and the focus has been on the role of these devices in teaching vocabulary to L2 learners. A feature 
of mobile phones that was initially widely used in the studies was the SMS (Short Message Service). In addition to the text messaging capabilities of SMS, also used MMS (Multimedia Messaging Service). MMS messages includes multimedia such as images and sounds.

In addition to the text messaging capabilities of SMS, Saran and Seferoglu also used MMS (Multimedia Messaging Service) in their study. While the experimental group was taught vocabulary via SMS and MMS messages that included multimedia such as images and sounds, the control group was taught the same vocabulary items in the classroom. The scores of the experimental group were significantly higher than the control group in the post test.

In their study, to compare the effects of SMS versus paperback dictionaries in academic vocabulary learning, found that there was no significant difference between vocabulary knowledge of two groups in the post tests; however, the SMS group was more successful in the delayed posttest. Furthermore, all these studies reported positive attitudes of students towards the use of SMS in vocabulary learning.

Platforms and programs other than messaging services were also used in teaching vocabulary on mobile devices. Thornton and Houser wanted to test the effectiveness of e-mails on mobile phones on vocabulary teaching. In the first 4 week-long experiment, they sent students mini vocabulary lessons via emails, which students received on mobile phones for the first 2 weeks, and via computers for the last 2 weeks. In the second experiment, students were divided into 2 groups, one of which received emails while the other had the same content as printed material. Students reported that using mobile phones was a more effective method and more preferable to computers and printed materials. The last experiment was the evaluation of a website that the authors, together with their students, developed to teach idioms. Vidioms included idioms with explanations, and examples through multimedia (sounds, images, videos). The authors asked a group of students to evaluate the website as they used it on mobile devices such as phones and PDAs. Students found the website significantly 'effective and enjoyable' to use on mobile devices. [Saran \& Seferoglu, 2010]

Basoglu and Akdemir conducted a study on vocabulary learning to see the difference of use of mobile phones and flashcards. They used a mobile application for experimental group giving the words for six weeks while the control group learned the same words with flashcards. Their study reported a significant difference between two groups as the experimental group did achieve significantly better in the multiple-choice posttest.

Another example is Stockwell who compared vocabulary learning on mobile phones and computers in relation to student achievement, task completion speed, and time for a 3- year period between 2007 and 2009. A Moodle-based system called VocabTutor was developed to run both on computers and mobile devices. Findings of the study showed no significant difference in terms of student scores; however, most students preferred using the system on computers with an increase of mobile phone use in 2009.

As a recent study that made use of smartphones, Wu created a mobile application called Word Learning-CET6 to teach vocabulary to a group of 70 Chinese college students. While the experimental group used the application, the control group was only reminded to study the vocabulary items on their own via text messages. The posttest results at the end of the experiment reported a significant different between two groups with experimental group outperforming the control group.

Nowadays, a lot of students have a mobile phone with Internet and camera. Here are some of the ideas that improve students' vocabulary:

1.Picture Hunt

Teacher put on the wall some pictures from previous lesson. Then teacher say one word. Pupils should take a photo of this word. This method will help you develop mindfulness and reinforce what you have learned. Also if you have older students in your class, you may say have to take a photo of something curricular or something red etc. It develops pupils' attention to detail and improves focusing during activities.

2.Role scene pictures

Another activity for learners to exploit the use of the camera. Pupils take a photo of particular scenes and then have to produce the story using a set number of images. Then pupils send pictures 
for teacher to print and then they can be presented in class. A variation of this activity is to get learners to create the same storyboard by using a listening/reading activity from pupil's book as the basis of story. It provides some structure if learners have difficulty to creatively produce a story. And of course, this method helps to expand vocabulary.

Ideas for mobile phone video projects

Pupils can consider a wide range of topics to produce a drama project with their mobile phones. To begin, they can get ideas from many popular programs on television, including talk shows, game shows, news specials, and parodies. Following are four ideas for projects that can be expanded or reduced to adapt to the requirements of semester length, class size, language level, and age group.

Project 1: A short film

To make a short film, students will have to decide whether to base it on fact or fiction. After composing a script for the different scenes, assigning roles, and rehearsing their parts, they record the performance. Since this category offers students a large spectrum of genre options, such as drama, action, horror, and comedy, it is highly likely that they will find something of interest.

Project 2: A documentary

A documentary offers numerous topic choices suitable to different age groups. Students can plan out how they are going to narrate and record details about something of real-life interest, such as their family life, their neighborhood, their pet, their school, or their friends.

Project 3: An instructional video

An instructional video is a challenge, as it requires providing a clear description of how to accomplish a task, such as cooking something from a recipe, building a dog kennel, or making a kite. For example, students can develop a four-act video to: (1) introduce a game, (2) describe the roles of players on the different teams, (3) explain the rules of the game, and (4) show the game actually being played.

Project 4: A commercial

Students can make a commercial by adapting an idea from an existing commercial or by making up one of their own. In the commercial they persuade the audience to buy something - such as a new beverage they have invented - by talking about the selling points and advantages of the drink. They write the text in English, rehearse it, and then act out the commercial while filming the production with a mobile phone.

In addition to providing meaningful and real-world language experience, Skehan (1998) lists two other important elements of project-based tasks: (1) students work towards a goal, and (2) the activity is evaluated by its outcome. A mobile phone project consists of several stages done both in and outside of class. All of these stages can be graded independently, including the drafting of scripts, peer review and revision, and rehearsals of the film. To give feedback and evaluation of the final outcome, teachers and students can use a video assessment instrument like the rubric in Table 1, which lists six criteria and allows for a maximum score of 24 points. A mobile phone drama project can also be assessed through the Internet by uploading the videos to a website, preferably an official site under Ministry of Education, and having students, teachers, parents, and academicians evaluate and rank them. Then, at the end of the school year, the best works for each drama category can be selected and given awards by the Ministry of Education. Some of the drama productions may also compete in national or international competitions. With a video project, students produce something tangible that they can keep in their portfolios or personal albums to show their parents, friends, or perhaps their grandchildren. Moreover, students will see themselves actually speaking English. All of these factors will come together to give them a sense of accomplishment.

\section{CONCLUSIONS}

Vocabulary learning is one of the most important aspects of language teaching. Idioms, an essential part of vocabulary knowledge, and idiomatic knowledge can help learners to become proficient in the target language.

However, learning idioms is a major difficulty for many language learners in achieving a more natural sounding target language competence. When it comes to teaching idioms, it becomes more 
difficult since it is hard to predict their meaning with the first look (Zhang, 2009). Therefore, there is a door of opportunities for creating appropriate environments to teach idioms, particularly with the use of broadly available technologies, one of which is through mobile applications.

Therefore, using the smartphone applications that are already well-functioning and popular among users could facilitate the mobile learning practices considerably. A good example of these applications is WhatsApp, a free mobile messenger application that allows its users to exchange texts, as well as multimedia both in one-to-one and group conversations, and make calls. Being one of the most popular and widely used messenger applications, it is also available for all mobile platforms (IOS, Android, Windows Mobile, Symbian etc.). This study aims to investigate the use the effectiveness of this mobile application on teaching 40 figurative idioms from the MICASE corpus compared to traditional activities. Results of this study indicate that both the participants in the control and the experimental group significantly improved their knowledge of the target idioms independent of the activity type used in their respective groups. However, based on the posttest results, participants in the experimental group who learned idioms through the use of the mobile application achieved significantly better than their counterparts in the control group with traditional activities, indicating that use of the mobile application was more effective in teaching idioms than the traditional activities.

\section{REFERENCES:}

Alexandrov M.O. One Approach for the Realization of an Online Poker Game - Funpoker. Proceedings of IX International scientific conference "Science and Education", Kemerovo State University, Belovo Institute (branch), March 28-29, 2012, Belovo, Russia. Vol.1., pp. 124-127

Arsova, D. (2021). Skills and competencies of the new generation of students to work with digital devices // "Innovations in technology and education": proceedings of XIV International scientific conference "Innovations in technology and education", 26 march 2021 г.: Kuzbass State Technical University, Belovo, Russia; 2021. - vol. 3., pp. 59-66

Arsova, D. (2020). Developing of the elementary school students skills in a digital world // "Innovations in technology and education": proceedings of XIII International scientific conference "Innovations in technology and education", 26 march 2020 г.: Kuzbass State Technical University, Belovo, Russia; 2020. - vol. 4., pp. 55-60. ISBN 978-5-00137-065-9

Cooper, T. C. Teaching idioms// Foreign Language Annals №31(2), 1998.: p. 255-266.

Hayati, A., Jalilifar, A., \& Mashhadi, A. Using Short Message Service (SMS) to teach English idioms to EFL students// British Journal of Educational Technology №44(1), 2013.: p. 66-81.

Goletiani, K., Mushkudiani, Z., Gulua, E., Janelidze, N. (2021). Difficulties in managing diversity in Georgian educational organizations. Access to science, business, innovation in digital economy, ACCESS Press, 2(2): 123-137. https://doi.org/10.46656/access.2021.2.2(1)

Petrova, M., Aleksandrov, M. (2018). Automating the virtual hosts maintenance in a multi-site environment. International Congress on Business and Marketing (ICBM'18), Marmara Eğitim Köyü Maltepe / İstanbul, TÜRKIYYE, Proceedings of the International Congress on Business and Marketing, 2018 Maltepe University, Istanbul, ISBN 978-605-2124-09-03, p.392-404

Saran, M. \& Seferoglu, G. Supporting foreign language vocabulary learning through multimedia messages via mobile phones// Hacettepe University Journal of Education №38, 2010.: p. 252266.

Sushchenko, O., Akhmedova, O., Stryzhak, O. (2021). The use of interactive training technologies in teaching academic disciplines for students of tourism specialities. Access to science, business, innovation in digital economy, ACCESS Press, 2(1): 28-39. https://doi.org/10.46656/access.2021.2.1(3) 